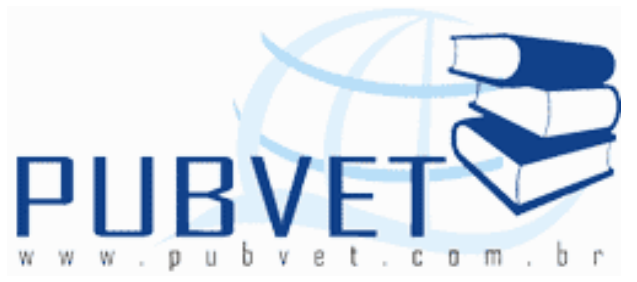

PUBVET, Publicações em Medicina Veterinária e Zootecnia.

\title{
Modificações ambientais em instalações para ovinos em sistemas de pastejo e confinamento
}

\footnotetext{
Tiago Adriano Simioni ${ }^{1}{ }^{*}$, Fagner Junior Gomes ${ }^{1}$, Claudio Jonasson Mousquer ${ }^{2}$, Ubiara Henrique Gomes Teixeira ${ }^{1}$, Wanderson José Rodrigues de Castro $^{2}$, Diego Cordeiro de Paula ${ }^{1}$, Alvair Hoffmann ${ }^{1}$, Geferson Antonio Fernandes ${ }^{3}$

1 Mestrandos em Zootecnia, UFMT/ICAA - Sinop-MT

${ }^{2}$ Mestrandos em Ciência Animal, UFMT/FAMEVZ - Cuiabá-MT

3Zootecnista, UFMT, campus de Sinop-MT, Brasil

*E-mail: simioni@zootecnista.com.br
}

\section{Resumo}

As instalações estão fundamentadas na extrema capacidade que elas têm em buscar a otimização da relação homem/animal/ambiente, dentro de um processo de produção, isto é, elas têm como funcionalidade, facilitar e reduzir o uso da mão de obra para as tarefas diárias, favorecem o manuseio do rebanho e o controle de doenças, protegem e dão segurança aos animais, dividem pastagens, armazenam e reduzem o desperdício de alimentos. Modificações ambientais devem ser planejadas de modo a proporcionarem as melhores condições possíveis de conforto térmico aos animais. Objetivou-se a discutir as principais características das instalações de ovinos e soluções para 
SIMIONI, T.A. et al. Modificações ambientais em instalações para ovinos em sistemas de pastejo e confinamento. PUBVET, Londrina, V. 8, N. 6, Ed. 255, Art. 1689, Março, 2014.

tal característica, otimizando e potencializando ao máximo o desempenho dos animais de produção.

Palavras-chave: manejo, conforto térmico, zootecnia

\section{Abstract}

The facility is based on extreme capacity they have to seek the optimization of the human/animal/environment, within a production process, ie, they have as functionality, ease and reduce the use of labor for everyday tasks favor the handling of the herd and disease control, protect and give security to the animals, divide pastures, store and reduce food waste. Environmental improvements should be planned so as to provide the best possible conditions for thermal comfort to animals. The objective is to discuss the main characteristics of facilities Sheep and solutions to such feature, optimizing and leveraging the maximum performance of livestock.

Keywords: management, thermal comfort, animal science

\section{Introdução}

O corpo animal é afetado por diferentes fatores externos, que exercem influência sobre o seu desempenho. O clima destaca-se como um fator determinante na produção animal por causa da geração de um ambiente térmico no espaço ocupado pelo animal e seus arredores. A caracterização do ambiente térmico animal envolve, principalmente, os efeitos de temperatura do ar, a umidade relativa, a radiação, a precipitação pluviométrica e a velocidade do vento (Raslan, 2008).

A importância da adequação climática das instalações para a criação de animais reside em sua estreita ligação com a produtividade e a economicidade do empreendimento rural. As crescentes pressões para o aumento da produção no campo, a competitividade dos mercados interno e externo, e a necessidade de conservação dos recursos ambientais apontam para a maior racionalização dos processos produtivos e, conseqüentemente, das instalações, 
SIMIONI, T.A. et al. Modificações ambientais em instalações para ovinos em sistemas de pastejo e confinamento. PUBVET, Londrina, V. 8, N. 6, Ed. 255, Art. 1689, Março, 2014.

na medida em que estas podem ser projetadas para oferecer as melhores condições de desenvolvimento da criação (Kawabata, 2003).

As mudanças e variações climáticas representam um desafio em manter a produção animal, pois alteram as condições fisiológicas dos animais ocasionando declínio na produção, principalmente no período de menor disponibilidade de alimentos.

Dessa maneira, as modificações feitas no ambiente possibilitam aos animais alcançar maior produtividade em função de um conforto térmico maior principalmente no Brasil onde $2 / 3$ do território situa-se nos trópicos (figura 01 ), com temperatura média anual superior a $20^{\circ} \mathrm{C}$.

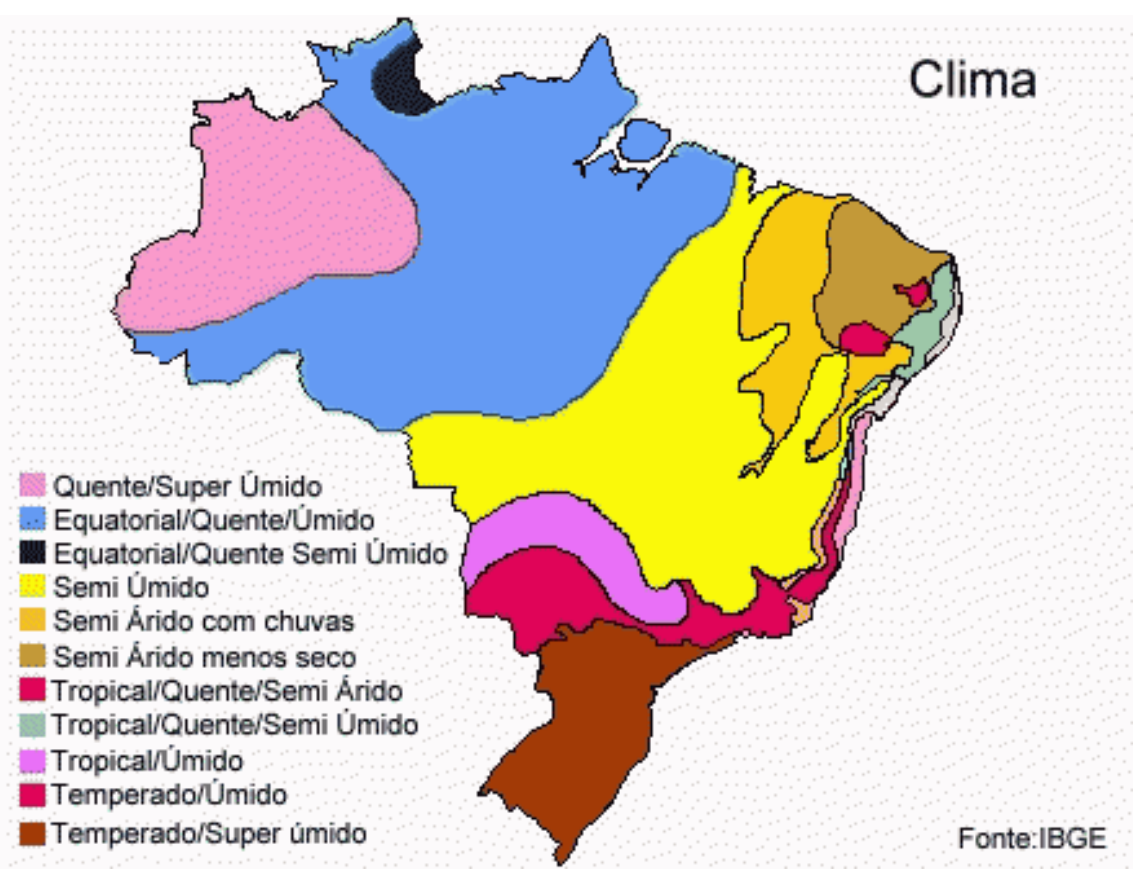

Figura 01 - Mapa do clima do Brasil.

\section{Índices de conforto térmico}

As modificações ambientais devem ser planejadas de modo a proporcionarem as melhores condições possíveis de conforto térmico aos animais. Existem diversos índices para mensurar o nível de conforto térmico. 
Estes são dependentes de vários parâmetros interrelacionados como temperatura, umidade relativa do ar, velocidade dos ventos e radiação solar.

Uma classificação dos índices de conforto térmico foi proposta por Nããs (1989) citado por Fonseca (2010), de acordo com a maneira com que eles foram desenvolvidos:

- Índices biofísicos: são aqueles baseados nas trocas de calor entre o corpo e o ambiente, correlacionando os elementos de conforto com as trocas de calor que os originam.

- Índices fisiológicos: são aqueles que se baseiam nas relações fisiológicas originadas por condições conhecidas de temperatura ambiente, temperatura radiante média, umidade relativa do ar e velocidade dos ventos.

- Índices subjetivos: são os que se baseiam nas sensações subjetivas de conforto, experimentadas nas condições em que os elementos de conforto térmico variam.

$\mathrm{Na}$ tabela abaixo se encontram os valores de temperatura crítica para ovinos.

Tabela 01 - Temperaturas críticas inferiores e superiores e zona de conforto térmico para ovinos.

\begin{tabular}{lccc}
\hline Animal & TCI & TCS & ZCT \\
\hline Cordeiros recém & $6^{\circ} \mathrm{C}$ & $34^{\circ} \mathrm{C}$ & 25 a $30^{\circ} \mathrm{C}$ \\
Ovinos adultos & $-20^{\circ} \mathrm{C}$ & $35^{\circ} \mathrm{C}$ & 15 a $30^{\circ} \mathrm{C}$ \\
Ovinos lanados (12 cm de lã) & $-4^{\circ} \mathrm{C}$ & $34^{\circ} \mathrm{C}$ & \\
Ovinos lanados (20 a $30 \mathrm{~cm}$ de lã) & Até $-20^{\circ} \mathrm{C}$ & $35^{\circ} \mathrm{C}$ & \\
\hline
\end{tabular}

Fonte: Raslan (2008)

\section{Clima e comportamento}

Existe uma crescente preocupação com o conforto térmico e com o comportamento animal e os conhecimentos gerados em função de 
SIMIONI, T.A. et al. Modificações ambientais em instalações para ovinos em sistemas de pastejo e confinamento. PUBVET, Londrina, V. 8, N. 6, Ed. 255, Art. 1689, Março, 2014.

investigações nesse sentido, têm sido utilizados com uma freqüência cada vez com maior para melhorar as estratégias de manejo e ajudar no desenvolvimento de novas técnicas de produção.

Um "ambiente ótimo" e "não estressante" exerce uma importância fundamental na fisiologia e na exploração econômica dos animais nele produzidos. Por isso, a avaliação comportamental dos animais em seus ambientes é uma ferramenta fundamental para estabelecer ou modificar o manejo e as instalações, buscando-se, por meio dela, manter o bem-estar dos mesmos e melhorar o trabalho dos manejadores (Albright, 1993). Nesse sentido, o conhecimento do comportamento animal torna-se importante, pois possibilita promover o melhor ajustamento da produção animal (Raslan, 2008).

De acordo com Cardoso (2005), citado por Raslan (2008), os ruminantes adaptam-se às diversas condições de alimentação, manejo e ambiente, podendo, ainda, alterar seus comportamentos ingestivos, buscando manter o nível de consumo de acordo suas exigências nutricionais.

O comportamento ingestivo dos ruminantes em pastejo pode ser caracterizado pela distribuição desuniforme de uma sucessão de períodos definidos e discretos de atividades, comumente denominados ingestão, ruminação e repouso. Geralmente, a ingestão ocorre de modo mais intenso durante o dia, de modo que a duração das refeições é mais variável que a duração dos períodos de ruminação ou descanso (Albright, 1993).

Em trabalho realizado para avaliar o comportamento de pastejo de ovinos em ambiente tropical, Starling et al. (1999) concluíram que, no período diurno, os animais permaneceram mais tempo na atividade de pastejo, seguido pela ruminação e descanso à sombra. Além disso, permaneceram mais tempo deitados do que em pé. $O$ aumento na temperatura máxima diária reduziu, também, seus tempos de pastejo.

Denota-se que as observações comportamentais, mais usualmente nas últimas décadas, vêm permitindo que alguns criadores aprimorem o manejo dos animais, reduzindo seus graus de estresse $e$, conseqüentemente, melhorando a produtividade (Albright, 1993). Por isso, a observação 
SIMIONI, T.A. et al. Modificações ambientais em instalações para ovinos em sistemas de pastejo e confinamento. PUBVET, Londrina, V. 8, N. 6, Ed. 255, Art. 1689, Março, 2014.

comportamental é considerada relevante, devendo ser mais bem estudada, pois pode possibilitar que se produza: de acordo com as exigências dos animais, com menos custos, com mais qualidade e precocidade.

\section{Bem-estar animal}

Dentre as definições mais aceitas para bem-estar animal está a de Broom et. al., (2004) citado por (Fonseca, 2010), em que "bem-estar de um indivíduo é seu estado em relação às suas tentativas de se adaptar ao seu ambiente".

Uma forma de colocar em prática o conceito de bem-estar animal é a verificação do grau de dificuldade que este animal demonstra na sua interação com o ambiente. As ferramentas das quais dispõe para contornar inadequações presentes em seu meio são utilizadas mais intensamente à medida que aumenta o grau de dificuldade encontrado. Estes instrumentos para enfrentar as dificuldades têm em sua grande maioria um caráter fisiológico ou comportamental. Conseqüentemente, certas alterações da fisiologia e/ou do comportamento de um animal podem ser indicativas de comprometimento de seu bem-estar. Tais alterações podem ser medidas de forma objetiva e constituem uma importante estrutura de avaliação do bemestar (Fonseca, 2010).

\section{Respostas fisiológicas}

Os animais se comportam segundo determinados padrões de atitudes que podem ser um ato único ou uma série de atividades e, usualmente representam uma resposta do animal a algum estímulo ambiental. Uma dada alteração ambiental estimula mais de uma resposta comportamental, mas o animal aprende a usar aquela que mostra ser mais eficiente.

\section{Temperatura retal}

A temperatura corporal resulta do equilíbrio entre a quantidade de calor produzida no organismo, ou por ele absorvida, e a quantidade liberada para o 
ambiente. Essa temperatura corporal pode ser medida através da temperatura retal (TR).

A TR sofre interação com a hora do dia, apresentando um maior valor durante o período da tarde em relação ao da manhã, variando também com a categoria animal.

A temperatura retal é, geralmente, um bom índice da temperatura corporal. Cardoso (2005), citado por Raslan (2008), dizem que a temperatura retal é resultante das trocas de calor com o ambiente, sendo dependente das condições deste, e da habilidade do animal em dissipar o excesso de calor. Além disso, a temperatura retal é freqüentemente usada como índice de adaptação fisiológica aos ambientes quentes, pois seu aumento mostra que os mecanismos de liberação de calor tornaram-se insuficientes para manter a homeotermia.

De acordo com Bacari Júnior (1998), citado por Raslan (2008), a temperatura retal em caprinos e ovinos varia de 38,5 a $40,0^{\circ} \mathrm{C}$ e vários fatores são capazes de causar variações na temperatura corporal, entre as quais estão: idade, sexo, estação do ano, período do dia, exercício e ingestão e digestão de alimentos; por isto, a temperatura retal é considerada a medida que melhor representa a temperatura do núcleo corporal, além de ser bastante utilizada para verificar o grau de adaptabilidade dos animais, por ser considerada bom indicador de estresse calórico.

\section{Freqüência respiratória}

A elevação da freqüência respiratória é um dos primeiros sinais visíveis de estresse térmico e, em termos de resposta, é a terceira na seqüência dos mecanismos de termorregulação. O aumento ou a diminuição da freqüência respiratória depende: da intensidade e da duração do estresse ao qual os animais são submetidos do período do dia; da temperatura ambiente; e do nível de produção animal (Raslan, 2008). 
SIMIONI, T.A. et al. Modificações ambientais em instalações para ovinos em sistemas de pastejo e confinamento. PUBVET, Londrina, V. 8, N. 6, Ed. 255, Art. 1689, Março, 2014.

\section{Criação de ovinos em sistema extensivo}

Este sistema de criação é voltado para a produção de carne de forma tradicional. Não é necessária a construção de instalações grandiosas.

De acordo com o tamanho do rebanho, será necessário formar bons pastos que devem ser suficientes para poder dispensar suplementação. Recomenda-se fazer uma análise do solo para correção de deficiências (calagem). O pasto deverá ser preferencialmente em terras altas, dividido em piquetes para fêmeas gestantes e recém-paridas, borregos e borregas, reprodutores, cordeiros de 2 a 6 meses, capões e ovelhas solteiras. Se não houver aguada natural no local de pastagem, providenciar bebedouros higiênicos, que deverão ser mantidos sempre limpos. Se não houver abrigos naturais, como árvores de boa copa ou bosques, construir abrigo rústico de sapé, com capacidade compatível ao tamanho do rebanho; sob o abrigo, providenciar cocho para sal mineral (Freitas et. al., 2005).

As cercas entre piquetes deverão ser construídas com mourões a cada 10 $\mathrm{m}$, intercalados com 4 ou 5 balancins; formada com seis a sete fios de arame liso. Recomenda-se que o primeiro, de baixo para cima, esteja a $10 \mathrm{~cm}$ do solo e a seguir o espaçamento entre eles seja, consecutivamente: 18,22 e $28 \mathrm{~cm}$ para os demais, numa altura total de 1,24 m. Quando em consórcio com bovinos, recomenda-se espaçamento de 10,15, 20, 25, 30 e $35 \mathrm{~cm}$, com altura de 1,30 m (total). Se necessário, construir um aprisco,(cabanha) para proteção, próximo às pastagens, em terreno seco e ensolarado.

A construção poderá ser rústica, com piso ripado $(1,5 \mathrm{~cm}$ de espaçamento), elevado a 1 metro do solo, pé direito de $2,5 \mathrm{~cm}$ para uma boa aeração e com paredes de 1,5 m de altura. A área recomendada por cabeça é de $1,5 \mathrm{~m}^{2}$ de altura. A cabanha é recomendada quando a criação for para matrizes e reprodutores. Deve ter divisões internas (boxes) medindo $2 \times 2$ a 2 x 3 metros cada um, com comedouro e bebedouro.

É imprescindível a construção de um curral de manejo, dividido em mangueiras e bretes, para os trabalhos de vacinação, marcação, descola (descaudamento, corte de cauda), vermifugação etc., de acordo com o 
tamanho do rebanho (recomenda-se $1 \mathrm{~m}^{2}$ / cabeça). Para contenção, seringa em área coberta, com tronco de $90 \mathrm{~cm}$ de altura $\times 50 \mathrm{~cm}$ de largura no alto e $30 \mathrm{~cm}$ no baixo; pedilúvio de $10 \mathrm{~cm}$ e banheira anti-sárnica profunda, para imersão, com curral, para escoamento contíguo para evitar desperdício do produto. Todo o corredor lateral da seringa deve ter piso a $50 \mathrm{~cm}$ do solo, para facilitar os trabalhos. Para rebanhos grandes, é necessário um galpão e tosquia. O pasto é o principal alimento dos ovinos e quando este é de boa qualidade a suplementação pode ser mínima. É preferível fornecer pastagens mistas, formadas por gramíneas e leguminosas (Freitas et al., 2005).

Devido ao sistema adotado (extensivo de larga escala) é preciso providenciar piquetes para as diversas categorias: ovelhas de cria e seus cordeiros; ovelhas velhas e falhadas, borregos (as) ovelhas no terço final da gestação, etc. As ovelhas de cria são separadas segundo a qualidade de suas lãs, ou por seu grau de sangue. Quando o plantel possui pedigree, destinar piquetes de melhor qualidade e de fácil vigilância.

Os carneiros reprodutores, fora da época de monta, são postos em boxes separados ou em outras construções. Utilizar a construção de abrigos para a proteção dos animais contra as chuvas e ventos fortes.

É indispensável à construção de banheiro sarnífugo para o combate da sarna. Deve possuir escorredouro, currais e bretes para a separação e mangas de contenção. As mangas e os bretes devem ser aparelhados de modo a permitirem a aplicação de vacinas, vermifugação e demais tratamentos e operações que se fazem no rebanho.

A construção de um galpão apropriado para a tosquia ou tosa, é necessário, devendo o mesmo ser feito nas proximidades dos currais e bretes, para evitar movimentação e despesas no criatório. Nas grandes propriedades deve-se prever a construção de bretes giratórios, destinados à inseminação artificial. 
SIMIONI, T.A. et al. Modificações ambientais em instalações para ovinos em sistemas de pastejo e confinamento. PUBVET, Londrina, V. 8, N. 6, Ed. 255, Art. 1689, Março, 2014.

\section{Modificações ambientais em sistema de pastejo}

No sistema de criação extensiva, os animais permanecem a maior parte do seu ciclo de vida nas pastagens. Portanto, estão sujeitos aos efeitos dos estressores climáticos.

As modificações nesse tipo de ambiente são essenciais para elevar o desempenho produtivo dos animais em regiões de clima tropical. A manutenção de ovinos em crescimento em condições de pastejo deve prever a suplementação alimentar com concentrados.

De acordo com Neiva et al. (2004), o tipo de dieta influencia de forma significativa a susceptibilidade dos animais aos efeitos ambientais. Desta forma, as interações entre tipo de alimento, consumo, ambiente e parâmetros fisiológicos devem ser avaliadas, visando melhorar o desempenho dos animais em regiões quentes.

O sombreamento em pastagem é a principal forma de modificação ambiental nesse tipo de sistema.

Existem basicamente dois tipos de sombreamento de acordo com Raslan (2008):

- Sombreamento Natural: ideal para pasto, o sombreamento natural bloqueia a radiação solar e a evaporação de água pelas folhas do mesmo, o que reduz a temperatura na sua proximidade, sem interferir na circulação do ar. A utilização mais indicada para evitar a radiação solar é a de árvores, preferencialmente com copa frondosa e alta, de no mínimo dois e no máximo três metros de altura.

- Sombreamento Artificial: pode ser feito através de estruturas permanentes ou portáteis. As últimas, apesar de menos eficientes, são mais econômicas e possuem a vantagem de poderem ser transportadas de um lugar para outro. Na construção, são utilizadas palhas e telas de polietileno conhecidas como sombrite, que possui uma resistência aos raios ultravioletas capaz de gerar de $30 \%$ a $90 \%$ de sombra. 
Sabe-se que produtividade é o contrário de rusticidade. Isto significa que todo animal, de alta produção, necessita de melhores cuidados. Assim, a proteção contra o clima torna-se necessária em qualquer local.

Vários autores relatam que a avaliação da produção de ovinos nas condições locais vem se apresentando de fundamental importância para a correção ambiental ideal e adequação das instalações dos animais, trazendo um maior bem-estar aos mesmos, o que seria mais um marketing comercial, haja vista a crescente demanda pela carne deste animal e, em conseqüência, por tecnologias que viabilizem o negócio não só do ponto de vista técnico e econômico, mas que sejam ecologicamente corretas e socialmente justas (Raslan, 2008).

Andrade et al. (2006) realizaram um experimento com o objetivo avaliar o efeito do sombreamento e da suplementação com concentrado sobre o comportamento fisiológico e desempenho de ovinos Santa Inês em pastejo no semi-árido paraibano. Os animais foram distribuídos aleatoriamente em três ambientes [sem sombra (SS), sombra natural (SN) proveniente de cajueiro e sombra artificial (SA) constituída por uma tela de polietileno com $80 \%$ de retenção] e alimentados com três níveis de suplementação concentrada. Eles verificaram que a freqüência respiratória foi maior no turno tarde do que no da manhã nos ambientes de SS e SA (tabela 02) e que temperatura superficial foi mais elevada no turno da tarde do que pela manhã, sendo maior para os ambientes de SS e SA (tabela 03). Conclui-se com esse experimento que o uso de sombreamento nas pastagens melhora os índices de conforto térmico do ambiente. 
Tabela 02 - Médias de freqüência respiratória (FR), em função do ambiente e do turno.

FR (mov/min.)

\section{Turno}

Ambiente

Sem sombra

Sombra natural

Sombra artificial

\section{Manhã}

$35,28 \mathrm{Ba}$

$30,00 \mathrm{Aa}$

$30,28 \mathrm{Ba}$
Tarde

$61,64 \mathrm{Aa}$

$35,59 \mathrm{Ac}$

$51,76 \mathrm{Ab}$

CV $(\%)$

17,48

Fonte: Andrade et al. (2006)

Tabela 03 - Médias de temperatura superficial (TS), em função do ambiente e da dieta, em dois turnos estudados (manhã e tarde).

TS $\left(\mathbf{C}^{\circ}\right)$

Ambiente

Sem sombra

Sombra natural

Sombra Artificial
Manhã

31,69Ba

$31,39 \mathrm{Ba}$

$31,88 \mathrm{Ba}$
Tarde

$38,55 \mathrm{Aa}$

$32,17 \mathrm{Ac}$

$33,71 \mathrm{Ab}$

\section{Dieta}

$0 \%$

$31,97 \mathrm{Ba}$

$34,06 \mathrm{Ab}$

$1,00 \%$

$31,65 \mathrm{Ba}$

$35,41 \mathrm{Aa}$

$1,50 \%$

$31,34 \mathrm{Ba}$

34,97Aa

CV (\%)

Fonte: Andrade et al. (2006)

\section{Criação de ovinos em sistema intensivo}

Segundo Martins et al. (2009), a terminação de cordeiros em confinamento é uma prática que consiste na seleção e confinamento de ovinos jovens, machos e/ou fêmeas, com vistas a prepará-los para o abate, num curto espaço de tempo, mesmo durante a época de carência alimentar nas pastagens. Isso tem causado boas expectativas no âmbito do setor produtivo, 
SIMIONI, T.A. et al. Modificações ambientais em instalações para ovinos em sistemas de pastejo e confinamento. PUBVET, Londrina, V. 8, N. 6, Ed. 255, Art. 1689, Março, 2014.

em função da redução de custos obtida com o confinamento na época seca. Outras vantagens da terminação de cordeiros em confinamento são:

- Reduz a idade de abate de 10 a 12 meses para 05 a 06 meses;

- Disponibiliza a forragem das pastagens, que já é escassa para as demais categorias de animal do rebanho;

- Agiliza o retorno do capital aplicado;

- Permite a produção de carne de boa qualidade, também na época seca ou na entressafra;

- Contribui para a produção de peles de primeira categoria, auferindo uma receita indireta ao processo de terminação de cordeiros;

- Tem garantia de mercado para os produtos carne e pele.

Ao iniciar o confinamento, os cordeiros deverão apresentar, no mínimo, de $15 \mathrm{~kg}$ de peso vivo e após 70 dias alcançarem um peso corporal da ordem de 26 a $30 \mathrm{~kg}$. Nas condições descritas acima, a carne dos cordeiros atende, prontamente, às exigências do mercado consumidor. A simplicidade da prática tem se apresentado como uma solução de mercado para muitos produtores, sobretudo para aqueles que povoam as áreas semi-áridas do Nordeste brasileiro, notadamente, durante a fase da carência alimentar nas pastagens nativas.

Cordão et al. (2010) ao avaliar respostas fisiológicas de cordeiros Santa Inês em confinamento, notou que pela manha a zona de conforto térmico estava adequada as exigências dos animais, porém no período da tarde os animais apresentaram uma maior freqüência cardíaca devido a elevação da temperatura. A UR estava na zona de conforto térmico dos animais, assim indicando que sem temperatura de conforto térmico adequada a UR relativa por si só, não consegue manter o conforto térmico desses animais. A temperatura retal no período da tarde teve um aumento de $1,55^{\circ} \mathrm{C}$ em relação ao período da manha.

Ao estudar cordeiros da raça Santa Inês em confinamento em duas situações, sendo uma com animais criados ao sol e animais criados a sombra, 
Neiva et al. (2004), constatou que o consumo de MS foi maior para animais que estavam no confinamento à sombra, assim ganhando mais peso durante o experimento, porém não foram observadas diferenças estatísticas no consumo de FDN e PB. Os animais criados à sombra tiveram um consumo de água menor do que animais criados sem sombra, este fato ocorreu, provavelmente, como resposta à alta taxa de evaporação de água dos tecidos do animal, conseqüência das trocas de calor entre o animal e o ambiente. Animais criados na sombra tiveram um ganho de peso cerca de $30 \%$ à mais que os criados recebendo radiação solar direta (Freitas et. al., 2005).

\section{Instalações e modificações ambientais}

Como cordeiros são animais sensíveis a chuva e sol intensos, confinamentos dessa classe ovina deve ser coberto, pois assim possibilita a produção de cordeiros o ano todo. No período chuvoso criações extensivas de confinamento tanto de bovinos quanto de ovinos ficam restritos devido ao acúmulo de lama dentro dos piquetes, fazendo com que animais diminuam consumo e assim ganhando menos peso.

\section{Aprisco}

$\mathrm{Na}$ construção das instalações devem ser considerados: condições ambientais, material disponível na região, qualidade dos animais; devendo as mesmas ser simples, funcionais e econômicas. Tais instalações podem ser construídas preferencialmente em locais secos, altos e pouco inclinados; protegidos dos ventos fortes e em solo compactado e ensolarado; próximo a uma fonte de água e de fácil acesso. Nas regiões onde as precipitações excedem $700 \mathrm{~mm}$ e se o aprisco for de chão batido, recomenda-se que este preferencialmente se situe na direção Norte-Sul. Essa é umas das modificações ambientais que visa impedir o aparecimento de problemas sanitários, haja vista que os ovinos são animais sensíveis aos parasitas. Vale lembrar que o tipo de material empregado na construção pode afetar de forma decisiva a ambiência das instalações, como também a cor das instalações. 
Aconselha-se a higienização semanal das instalações. A limpeza deve ser intensificada durante a maior ocorrência de parição e no período das chuvas. 0 esterco deve ser estocado fora do alcance dos animais, devendo ser utilizado nas áreas cultivadas, desde que bem curtido. Os tipos mais comuns de aprisco, segundo Brito \& Cunha (2000), citados por Soares et al. (2007) são:

- Chão batido - constituído de uma área aberta cercada de madeira, com uma parte coberta, podendo ter plataforma elevada com cerca de 30 a $50 \mathrm{~cm}$ de altura, de modo que as baias ocupem $1 / 3$ da superfície do galpão. Seu custo implantação é o menor de todos.

Piso suspenso - utilizado para animais em sistema de confinamento e semiconfinamento; apresenta melhores condições de manejo e higiene para os animais. O pé direito deve ser de 2,50m, o piso deve estar elevado a uma altura de $0,80 \mathrm{~m}$ do solo, utilizando na sua construção ripões de $3 \mathrm{~cm}$ de largura, distanciado de $1 \mathrm{~cm}$ para as áreas de cabrito e de $1,5 \mathrm{~cm}$ para as matrizes. As vigas que suportam os ripões devem ser espaçadas de aproximadamente 9,60m. As rampas de acesso com largura mínima de 1,20 m devem ser pouco inclinadas para facilitar a subida dos animais devendo possuir proteção nos lados para evitar a queda das crias. Esse tipo de aprisco permite uma passagem maior da ventilação natural melhorando a circulação de ar no interior da instalação, como mostrado na figura 02.

\section{Cochos e saleiros}

Os cochos são utilizados para arraçoar os animais com ração volumosa e/ou concentrada. Devem ficar localizados do lado de fora das instalações, evitando o desperdício e a contaminação por fezes e urina, além de facilitar o abastecimento; devem apresentar as seguintes dimensões: 30-40 cm de altura do solo, $20 \mathrm{~cm}$ de profundidade e $30 \mathrm{~cm}$ de largura.

Os saleiros é outra instalação de muita importância e de baixo custo, e deve ser fixado sob a área coberta do curral. 
SIMIONI, T.A. et al. Modificações ambientais em instalações para ovinos em sistemas de pastejo e confinamento. PUBVET, Londrina, V. 8, N. 6, Ed. 255, Art. 1689, Março, 2014.

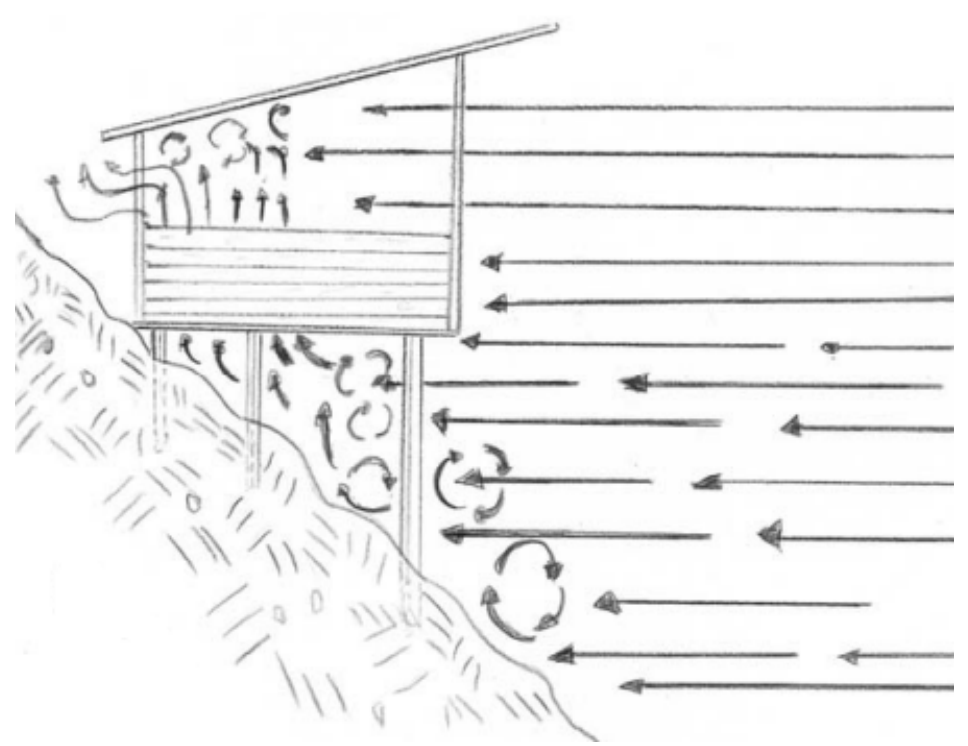

Figura 02 - Esquema de ventilação em um aprisco de piso suspenso.

\section{Pedilúvio}

A finalidade do pedilúvio é fazer a desinfecção espontânea dos cascos dos animais, toda vez que eles entrem ou saiam do aprisco. Os pedilúvios deverão ser construídos na entrada dos currais, apriscos ou chiqueiros, de tal modo a forçar os animais a passarem, pisando através deles.

Eles devem ter as seguintes dimensões: 2,0 m de comprimento com $10,0 \mathrm{~cm}$ de profundidade. A largura deve ser a mesma largura da porteira, que deve medir $0,75 \mathrm{~m}$.

Vários são os produtos que podem ser utilizados nos pedilúvios. a) solução de formol a $10 \%$; o sulfato de cobre a $10 \%$ e a cal virgem. A cal virgem diluída em água funciona como um bom desinfectante sendo mais barato que os demais.

\section{Isolamento}

O isolamento é uma instalação chamada também de "hospital". Ele destina-se a abrigar os animais doentes.

Sua construção deve seguir as mesmas recomendações do aprisco ou do chiqueiro, porém devem localizar-se bem distante destes, para evitar o contato 
de animais doentes com os sadios. De preferência, deve localizar-se longe de fontes de barulhos freqüentes e de movimentação de pessoas.

$\mathrm{O}$ isolamento deve oferecer o bem-estar e boas condições de higiene para os animais doentes.

\section{Brete}

Os bretes são instalações complementares de um centro de manejo. Devem ser centralizados e construídos de tal forma a permitir um fácil acesso dos animais.

O tamanho pode ser variado de acordo com o número de animais do rebanho. O modelo mais divulgado é de oito metros $(8,0 \mathrm{~m})$ de comprimento; com uma largura de 0,25 $\mathrm{m}$ na base e 0,35 $\mathrm{m}$ na parte superior e com uma altura de 0,85 m.

Os bretes são de grande utilidade para o manejo dos animais, no que diz respeito a vacinações, vermifugações, pesagens e outras práticas.

A balança para pesagem dos animais deve ficar na saída do brete, abrigada por uma cobertura para uma melhor proteção da mesma e oferecer uma condição favorável de sombreamento para o manejador.

\section{Esterqueira}

A esterqueira é uma construção reservada para depósito de esterco. Ela permite o melhor aproveitamento do esterco e contribui para melhorar as condições higiênicas da criação.

A esterqueira não deve ficar muito próxima das instalações, pois o esterco pode funcionar como reservatório de larvas de helmintos e de moscas ou como fonte de contaminação de outras doenças.

Afora a grande importância das esterqueiras, com relação às condições higiênicas do rebanho e a saúde dos animais, elas propiciam a produção de adubo orgânico de elevada qualidade.

A esterqueira pode ser de alvenaria, medindo $4,0 \mathrm{~m}$ de largura $\times 2,0 \mathrm{~m}$ de profundidade e $1,5 \mathrm{~m}$ de altura. 
SIMIONI, T.A. et al. Modificações ambientais em instalações para ovinos em sistemas de pastejo e confinamento. PUBVET, Londrina, V. 8, N. 6, Ed. 255, Art. 1689, Março, 2014.

\section{Considerações finais}

Os fracos índices produtivos e reprodutivos de ovinos criados de forma intensiva ou extensiva podem estar relacionados, dentre outros fatores, às falhas na elaboração e execução do projeto construtivo.

As deficiências no manejo das instalações podem redundar em perdas insensíveis para o sistema de produção de ovinos. Para evitar isso, se deve preocupar-se com as características construtivas ligada ao bem estar animal no momento da concepção do projeto.

No ambiente interno dos apriscos é fundamental importância que se dê prioridade aos aspectos construtivos que mais afetam a temperatura do ar, seguido por aquelas responsáveis pela elevação da umidade relativa do ar e as que serão capazes de promover uma excelente movimentação dos ventos pelas partes internas das instalações.

O conhecimento prévio das zonas de conforto de ovinos, em suas várias faixas etárias, assim como as temperaturas críticas mínima e máxima para todas as categorias do sistema produtivo garante base sólida para se pensar e executar um projeto com melhores características de ambiência.

\section{Referências bibliográficas}

ANDRADE, I. S., SOUZA, B. B., PEREIRA FILHO, J. M. et al. Parâmetros fisiológicos e desempenho de ovinos Santa Inês submetidos a diferentes tipos de sombreamento e a suplementação em pastejo. Ciência Agrotécnica, v.31, n.2, p. 540-547. 2007.

ALBRIGHT, J.L. Feeding behaviour of dairy cattle. Journal of Dairy Science, v. 76, p. 485 491, 1993.

BROOM, D.M.; MOLENTO, C.F.M. Bem-estar animal: conceito e questões relacionadas Revisão. Archives of Veterinary Sciense, v.9, n.2, p.1-11, 2004.

BACCARI JUNIOR, F. Adaptação de sistemas de manejo na produção de leite em climas quentes. In: SIMPÓSIO BRASILEIRO DE AMBIÊNCIA NA PRODUÇÃO DE LEITE, Piracicaba, 1998. Anais... Piracicaba-SP: FEALQ, 1998, p.24-67

BRITO, E.A. de; CUNHA, M. das G.G. Instalações para caprinos leiteiros. In:SOUSA, W.H de; SANTOS, E.S. dos. Criação de caprinos leiteiros: Uma alternativa para o semiárido. 2 ed. João Pessoa: SEBRAE-PB/EMEPA, 2000. p.191-207. 
CORDÃO, M. A; SOUZA, B; PEREIRA, G. M; BAKKE, O. A; SILVA, A. M. A; LOPES, J. J; Respostas fisiológicas de cordeiros Santa Inês em confinamento à dieta e ao ambiente físico no trópico semiárido. In: Agropecuária científica do semi-árido ISSN 1808-6845. v.06, n.01, p.47-51, 2010.

CARDOSO, I.P.M. Influência do sombreamento artificial em parâmetros fisiológicos e produtivos de vacas mestiças (Holandês X Zebu). 2005, 65f. Dissertação (Mestrado em Zootecnia). Itapetinga-BA: UESB, 2005.

FONSECA, P. C. F. Efeito do manejo de cobertura sobre índices de conforto térmico, variáveis fisiológicas e desempenho de bezerros leiteiros. 2010. 67p. Dissertação (Mestrado em Engenharia Agrícola) Universidade Estadual de Goiás, Unidade Universitária de Ciências Exatas e Tecnológicas, Anápolis.

FREITAS, J.V.F.; TEIXEIRA, D.I.A.; LOPES-JUNIOR, E.S.; PAULA, N.R.O.; ALMEIDA, A.P. Manejo reprodutivo de caprinos e ovinos. Do campus para o campo: Tecnologia para produção ovinos e caprinos. 1 ed. Fortaleza: Gráfica Nacional, 2005, p.241-263.

KAWABATA, C.Y. Desempenho térmico de diferentes tipos de telhado em bezerreiros individuais. 2003. 108p. Dissertação (Mestrado em Zootecnia) Universidade de São Paulo, Departamento de Zootecnia, Pirassununga.

MARTINS, E. C; GUIMARÃES, V. P; BOMFIM, M. A. D; Terminação de cordeiros em confinamento: avaliação econômicas, sociais e ambientais; In: Comunicado técnico on line EMBRAPA 109, ISSN 1676-7675, Sobral, Ce; Dezembro, 2009.

NEIVA, J. N. M.; TEIXEIRA, M.; TURCO, S. H. N. Efeito do estresse climático sobre os parâmetros produtivos e fisiológicos de ovinos Santa Inês mantidos em confinamento na região litorânea do nordeste do Brasil. In: Revista Brasileira de Zootecnia, Viçosa, v.33, n.3, p.668-678, 2004.

NÄÄS, I.A. Princípios de conforto térmico na produção animal. São Paulo: Ed. Ícone, 1989. $183 \mathrm{p}$

RASLAN, S. S. A. Aspectos comportamentais e fisiológicos de ovino SRD sob pastejo com e sem sombreamento. 2008. 98p. Dissertação (Mestrado em Zootecnia) Universidade Estadual do Sudoeste da Bahia, Itapetinga

SOARES, A. T; VIANA, J. A; LEMOS, P. F. B. A; RECOMENDAÇÕES TÉCNICAS PARA PRODUÇÃO DE CAPRINOS E OVINOS; In: Tecnol. \& Ciên. Agropec., João Pessoa, v.1., n.2, p.45-51, dez. 2007.

STARLING, J.M.C.; SILVA, R.G.; COSTA, M.J.R.P. et al. Comportamento de pastejo de ovinos em ambiente tropical. In: REUNIÃO ANUAL DA SOCIEDADE BRASILEIRA DE ZOOTECNIA, 36, 1999, Porto Alegre. Anais... Porto Alegre: SBZ, 1999. CD-ROM. 